Roberto MORA MARTÍNEZ

Universidad Nacional Autónoma de México

rmoramar@unam.mx

\title{
IDENTIDAD NACIONAL Y DIVERSIDAD CULTURAL, LOS RETOS DE LA CONVIVENCIA INTERCULTURAL EN NUESTRA AMÉRICA
}

ABSTRACT National identity and cultural diversity. The challenges of intercultural life in our America

This paper refers to Latin American identity problems. This subject is directly connected to the organization of different original ethnic groups in order to fight for a fair treatment. However, discussing Latin American unity implies ruling out some historical factors that might divide us. I assert that only if we recognize the ruling system of this native peoples, as well as their institutions, we will be able to build a respectful relationship between Latin Americans.

Keywords: identity, oblivion, assimilation, supranational organizations

Palabras clave: identidad, olvido, asimilación, organizaciones supranacionales 


\section{INTRODUCCIÓN}

El tema de la identidad se analiza en una doble perspectiva: la individual y la social. Para precisar las diferencias este trabajo inicia abordando algunas ideas generales en torno a este tema de la identidad. Lo cual es fundamental para sustentar una concepción identitaria, cuyos rasgos principales, puedo decir, se comparten en los diversos grupos sociales de América Latina y el Caribe.

Señalo la manera como las identidades en América Latina iniciaron su conformación a partir de la conquista llevada a cabo por los españoles, por lo que planteo la importancia de reconocer aquellos factores históricos que nos dividen como sociedad, por ejemplo el desprecio a la humanidad de los indígenas, de tal modo que para llevar a cabo una asimilación de nuestro pasado a través de la aceptación de una verdadera diversidad cultural, política, económica y jurídica, principalmente, no únicamente.

En este orden de ideas, es trascendental avanzar sobre el racismo y el clasismo imperante en América Latina, por lo que es valioso exponer los acuerdos de organización supranacional llevada a cabo por los integrantes de las naciones originarias que se están llevando a cabo en Sudamérica, ya que son luchas que exigen un trato justo pero diferenciado. Esto es, el esfuerzo por concretar el respeto de las diversas etnias, así como por sus sistemas de organización social.

\section{EL PROBLEMA DE LA IDENTIDAD}

\section{En lo individual}

Es necesario señalar que para el ser humano es una significativa constante antropológica el encontrar sus coordenadas específicas dentro de la infinidad de los procesos sociales. Esto es, entre los animales con los que comparte el mudo, en los humanos impera la necesidad de autoconocimiento en dos aspectos:

1) para algunas filosofías o religiones, la identidad individual ya se posee desde el nacimiento, por lo cual durante la vida debemos descubrirla y con esa base llevar a cabo el papel que venimos a cumplir en el mundo. Postura que sólo apunto y que por lo tanto no desarrollo. Sin embargo, debo señalar que hoy día dicha tendencia ha tenido gran una difusión a partir de las tendencias espiritualistas de la llamada Nueva era.

2) de lo propio como individuo, lo cual lo constituyen como único, a pesar de que comparta ciertos gustos y aficiones con otras personas. Con esta base, aceptar la existencia de un destino que se debe construir con base en la personalidad o carácter que se llegue a desarrollar, el cual es producto de las experiencias individuales, las cuales son resultado del azar. Por lo tanto, es el ser humano quien se debe dotar de un objetivo de vida. 
No está de más señalar que desde mi punto de vista no hay respuestas claras sobre la preexistencia o no de un destino. Por lo que, en mi opinión, cada ser humano debe hacerse responsable de confeccionar su destino.

Para el reconocimiento de los elementos internos de la identidad individual, es fundamental la construcción de una postura o filosofía de la vida, lo cual es un aspecto que pocas personas llevan a cabo. De ahí que un número sustancioso de personas adopten interpretaciones religiosas o doctrinas filosóficas, sin pretender crear una interpretación propia. Sin embargo, este último aspecto me permite transitar a la identidad comunitaria.

\section{La identidad en lo social}

Es posible apuntar que la identidad individual, es en buena medida una expresión de la identidad social, debido a que lengua, religión, ritos e incluso imágenes y en general la cultura, son aspectos que constituyen un alto porcentaje de las ideas de cada persona sobre sí misma. Lo cual desdichadamente, en gran número de casos impide encontrar aquellos elementos propios por la adopción costumbrista, enseñada institucionalmente o familiarmente, de los ámbitos aceptados socialmente.

De tal modo, es necesario señalar que es el aspecto comunitario en el que vamos a profundizar en este trabajo. Sin embargo, éste también presenta una doble problemática, una es histórica y la segunda es del presente:

1) Considero el factor histórico partiendo desde la perspectiva de la filosofía latinoamericana, en la cual la historicidad es la respuesta al ámbito que diferencia la actividad humana del restante conjunto de seres vivos. Esto significa que los registros sobre la manera como ha acontecido la interacción humana es lo que permite construir explicaciones sobre la manera como se forjan las caracteristicas específicas de cada agrupación bumana, ${ }^{1}$ su cosmovisión, moral, leyes, economía, etcétera, factores que conforman la identidad grupal.

Sin embargo, no todo desarrollo social es endógeno, pues a lo largo de la historia se puede verificar que distintas comunidades han entrado en contacto, principalmente, por tres medios: a) guerra, b) comercio y, c) casualidad, esta última debido a migrantes o viajeros. Todas estas formas de relacionarse han modificado las concepciones identitarias de los grupos que entran en contacto. Como caso ejemplificativo está nuestro pasado, pues el contacto entre indígenas e hispanos, entre otros grupos humanos, han dado lugar a una serie de sucesos que han negado las capacidades de los nacidos en América Latina y el Caribe, lo cual ha conformado una parte de la percepción identitaria de los nacidos en estas tierras.

Por otra parte, los diversos contactos humanos han provocado una variación en el número de personas que habitan algún territorio, ya que de ser pequeños

1 R. Mora Martínez, 'Los tres pilares de la filosofía latinoamericana', Archipiélago, Año 20, Núm. 80 (2013), p. 56. 
grupos nómadas se han ido modificando en número y complejidad organizativa, de las más diversas maneras, hasta conformar los actuales estados nacionales.

Debido a los diversos factores históricos, hoy día no es fácil determinar cuáles son los componentes esenciales de una identidad nacional, debido a que los Estado-nación latinoamericanos han aglutinado a diversas naciones indígenas sin una historia común, separando a otras cuya cultura es afín. El mejor ejemplo es de los mayas, quienes han sido divididos en por lo menos tres países, México, Guatemala y Honduras. En este punto se puede decir que al momento de edificar los estados nacionales, no se respetaron las fronteras culturales, dañando así a las culturas indígenas que se han visto sometidas a formas y modos de vida ajenos.

2) En el segundo aspecto de la identidad social, puedo señalar que en el presente, desafortunadamente, las relaciones entre pueblos con prácticas políticas y económicas diferentes, ha provocado en América Latina, así como en otras partes del mundo, que grupos humanos sean segregados, por no ajustarse a los patrones del capitalismo, ni a las prácticas políticas del liberalismo.

Por otra parte, no es factible olvidar otros grupos sociales que están luchando por el reconocimiento de sus derechos como los grupos feministas, los lésbico-gays o de mujeres e incluso de diversos grupos de jóvenes. Así, todos estos grupos y organizaciones sociales están modificando, hoy día, algunas percepciones identitarias tradicionales, que no está de más decirlo, no son estáticas. Aunque algunos seres humanos así lo deseen.

Hoy día, es notorio que la mayoría de los pueblos del mundo están enfrentando una lucha por sobrevivir en una economía excluyente, que no acepta modelos alternativos. En este punto es importante resaltar que se ha señalado a los sistemas colectivos de producción en las naciones originarias como alternativas para el capitalismo, lo cual es cierto, pero son sistemas aptos para grupos minoritarios, pues las ciudades en donde no se produce nada de comida tienen diferentes necesidades, por ello la importancia de mantener el sistema de agricultura y ganadería extensivas, pues sólo así se pueden satisfacer las demandas alimenticias.

Considero importante aclarar que el punto sobre los modos de producción en alimentos no es un tema menor, debido a que realmente es controvertido, pues para algunos, es necesario dejar de consumir carne pues el ganado, en su alimentación y sus heces, está provocando la devastación del mundo, para ello se ha propuesto como alimento sustituto la soya, la cual ha provocado gran deforestación en el Amazonas, así como en otros territorios en los que se le planta.

Debido a las diversas dificultades relacionadas con las diferentes necesidades sociales, es que la búsqueda de alternativas debe considerar la diversidad real, sin idealizar ninguna propuesta.

De tal modo que, el capitalismo globalizado ${ }^{2}$ se ha construido con base en un esque-

2 Es necesario, señalar que en otros trabajos hemos analizado el aspecto del capitalismo y su relación con el liberalismo, por lo que estamos en la posibilidad de señalar que en este trabajo, nos referimos al actual sistema capitalista que, hoy por hoy, está destruyendo el planeta, sin embargo, consideramos importante señalar que no es la única opción que se puede desprender de las concepciones liberales. 
ma de sobre explotación de la tierra y de acumulación de capitales en pocas manos, por ello los grupos que no han ingresado a este sistema son excluidos, precisamente por no contribuir a su desarrollo. Claro que sin olvidar, los inconvenientes del desprecio étnico y cultural. Problema que se ha agudizado hoy día, debido a que los actuales conflictos de narcotráfico, ataques a civiles, trata de mujeres, pobreza extrema han forzado a migrar núcleos considerables de seres humanos.

Lo que se ha dado en llamar la migración forzada, la que ha provocado que las personas que se alejan de su país de nacimiento conformen en otras naciones, asentamientos humanos que no quieren olvidar su origen cultural, pero que en ocasiones sus costumbres o prácticas sociales no concuerdan con las de la nación en la que se han establecido, lo cual desafortunadamente en ocasiones ha creado conflictos de convivencia.

A pesar de las dificultades que cotidianamente se viven en las relaciones entre diversos grupos humanos, es necesario señalar que la convivencia intercultural es posible. Pero, para comprender dicha posibilidad, primero es necesario profundizar en problemas relacionados con la misma creación de una identidad comunitaria, aspecto que es fundamental, para posteriormente explicar el problema de los términos con los cuales se ha abordado la relación ente diversas culturas.

\section{EL SENTIDO DE LA ADSCRIPCIÓN}

Abordé el tema de la identidad, en sus aspectos individual y social, así como unas breves líneas sobre la negación de la diferencia, por lo cual es necesario considerarla desde otros puntos de vista que permitan la creación de formas de convivencia abierta a la diversidad.

Una idea interesante sobre el inicio de la diferencia social, ha sido expresada por Xavier Etxeberria, quien señaló que cuando se genera una identidad colectiva, esta se basa en un "nosotros", también supone la exclusión de otro grupo en un "ellos". Idea que considero base para expresar el origen de algunos conflictos sociales, no por el hecho de que las culturas son tan diferentes que por sí mismas provoquen los conflictos, sino porque algunos de los contactos entre grupos humanos que a lo largo de la historia se suscitaron, provocaron aprietos que en la actualidad dividen a los miembros nacidos en los grupos participantes.

Entonces la reflexión formulada por Etxeberria, consiste en saber ¿qué modelos de pertenencia y exclusión pueden ser calificados como humanos?, en el sentido de que se constituyan como válidos éticamente. De tal modo que, para abordar esta pregunta es importante reflexionar sobre el sentimiento de adscripción.

La adscripción como sentimiento de formar parte de algún grupo, como se expuso líneas abajo, es una constante humana. Por lo que es la cultura de la población en la que se creció lo que dota a los individuos de una orientación o explicación sobre las permanentes dudas humanas, las cuales van desde el origen del sol o de todo lo que hay en el universo, hasta la respuesta del porqué muere la gente. De tal modo, que es a partir de las explicaciones que se han ido transmitiendo y modificando de generación en genera- 
ción, las cuales se refuerzan con un estilo de vida, que los seres humanos logran experimentar una existencia aceptable.

Sin embargo, el sentimiento de pertenencia de los individuos a un grupo cultural, se desarrolla en su máxima expresión cuando se suscitan choques violentos. Esto significa, que es cuando los propios elementos culturales y la vida misma son empleados para la defensa o son utilizados para atacar a otros, es que se concreta el sentido de pertenencia a un grupo.

No es mi pretensión señalar que la historia humana se ha desarrollado con base en las guerras, aunque éstas, efectivamente, han sido uno de los factores principales de transformación cultural. Sin embargo, no todos los intercambios sociales han sido por esta vía. Así, lo que me interesa destacar es que el sentimiento de adscripción por parte de los individuos, es el factor de arraigo, de pertenencia a un grupo humano, que por lo general comienza con el contacto familiar y continúa con el círculo de amigos, vecinos, conocidos, etcétera, lo que incluye un modo de vida, que al verse en riesgo de desaparición se vuelve más valioso, por el hecho de que es ahí en donde los seres humanos encuentran la raíz, esto es la explicación de su existencia.

En el caso de América Latina, es necesario señalar que remitirse a los sucesos ocurridos después del 12 de octubre de 1492, es invariablemente necesario, debido a que fue a partir de esa fecha que las culturas originarias se vieron enfrentadas a un proceso de conquista que modificó su percepción cultural.

En este sentido, no se debe olvidar que con la llegada de los españoles se modificó la concepción de religión, la vestimenta, las formas de trabajo a través de enseñar el empleo de diferentes herramientas, así como la alimentación, pues llegaron nuevas semillas y animales que hicieron más variada la comida. Asimismo, algunos grupos originarios también transformaron su organización política y social. Sin embargo, el cambio a pesar de haber sido brusco y por más violento, no eliminó los patrones culturales de los pobladores, de tal modo que el sentimiento de adscripción los ha llevado a asimilar los diversos aportes culturales con los que han tenido contacto. Por lo que afirman con orgullo, sobre todo hoy día, su carácter de naciones originarias. De tal modo que, se siguen denominando como Quechuas, Aymaras, Coras, Tzetzales, Tzotziles, etcétera.

\section{¿LA UNIDAD POR EL SENTIMIENTO DE ADSCRIPCIÓN?}

En la actualidad, como respuesta al proceso globalizador en el que hay una tendencia a querer homogenizar la cultura del mundo, la adscripción de los individuos a una expresión cultural específica ha servido para reafirmar lo valioso de la diversidad cultural.

En América Latina el trabajo realizado por un número considerable de seres humanos de los pueblos originarios, obedece a la tendencia a fortalecer la identidad comunitaria. En un número considerable de casos, se trata de poblaciones que se vieron divididas primero en la época de la conquista y después en el siglo XIX, por la invención de naciones que separaron pueblos con un origen común. Como ejemplo podemos indicar el caso de los mayas de México y de Guatemala, sin olvidar a los Yaquis, grupos origina- 
rios del norte que después de las invasiones norteamericanas quedaron divididos entre México y Arizona, así como los Pápagos que habitan en Sonora y Estados Unidos. Por otra parte, los grupos andinos quedaron divididos entre Perú, Bolivia, Chile y Argentina.

Además, ese proceso de creación de naciones unió a otros pueblos con procesos históricos diferentes. Por lo que los nacientes países tuvieron que crear nuevas identidades, así apareció lo peruano, lo argentino, lo mexicano, lo guatemalteco. Por lo que precisamente, hasta el momento, el fracaso de las nuevas identidades es que se impusieron estereotipos culturales de una región, la central o capital, sobre las otras.

De tal modo, que a esa nueva identidad nacional se le ha ido dotando en primer lugar de imposiciones simbólicas como los himnos y banderas nacionales, que en algunos casos son producto de la historia de un grupo específico, como es el caso del escudo nacional mexicano que proviene de la historia de los mexicas, por lo que se dejaron de lado otras tradiciones de los diversos pueblos originarios que también habitan en México. Ahora bien, a pesar de que la representación del águila devorando una serpiente puede considerarse como un rescate del pasado indígena, fue una imposición.

En este punto considero oportuno detener el trabajo sobre la manera como los estados nacionales del siglo XIX debilitaron a las naciones originarias, para expresar algunas reflexiones en torno al tema de la nación, ya que coincido con las ideas expresadas por Ernest Renán, sobre la manera como se puede concebir la creación de una nación en el sentido moderno.

\section{¿LA UNIDAD NACIONAL POR MEDO DEL OLVIDO?}

Inicio este acápite citando una idea que me parece interesante del trabajo de Ernest Renan, en la que afirma una nación [...] representa una antigua conquista aceptada primero y olvidada después por la masa del pueblo ${ }^{3}$.

La propuesta del párrafo anterior, según la cual, un pueblo olvida una conquista es interesante, debido a que indirectamente se hace alusión a la cuestionable idea del contrato social de Rousseau, sin embargo, en el caso de las naciones originarias de América Latina y el Caribe, es obvio que fueron forzadas a sumarse a un proyecto de país. Aspecto que no se puede olvidar, pero que no debe provocar divisionismos violentos. Si bien es cierto en la actualidad se requiere la creación de nuevas divisiones políticas, éstas se deben establecer para el establecimiento de mejores gobiernos que sirvan a la población. Con ello será posible asimilar históricamente aquellos pasajes históricos que dividen y enfrentan, pues no sólo están los pueblos originarios, también hay que señalar la importancia de considerar las diversas experiencias de los grupos urbanos que han sido afectados por los militares y la policía, por lo que no se trata de dejar de lado aspectos como las matanzas estudiantiles y en general atropellos contra las comunidades, ya que tener presente este tipo de atropellos permite crear conciencia en la sociedad.

3 E. Renan, ¿Qué es una nación? Cartas a Strauss, Madrid 1987, p. 63 (Libro de Bolsillo, 1294. Humanidades). 
Es importante afirmar que esa necesidad de avanzar sobre los sucesos negativos del pasado, no la concibo como la omisión o abandono de los acontecimientos de la historia, sino como la asimilación apuntada por Leopoldo Zea, quien basándose en Hegel, señaló que seremos capaces de asimilar nuestro pasado, cuando seamos capaces de negar lo que ya no nos es propio dentro de una lógica dialéctica, por lo que negar no significa eliminar sino asimilar, esto es, conservar. De acuerdo con esta lógica lo que se es, se es plenamente, para no tener necesidad de volver a serló ${ }^{4}$.

A pesar de las necesidades actuales de las naciones originarias, las cuales están planteando una nueva geografía política, no se debe olvidar que hoy están asentadas en una nación, con una economía común y un sistema político compartido, que es cierto ambos los han dañado. Sin embargo, es necesario considerar los diferentes factores que relacionan a los diversos grupos originarios, para proponer alternativas de creación de nuevas divisiones políticas realmente sólidas.

Avanzar en propuestas requiere de comprender a la nación moderna, por ello considero oportuno continuar con las ideas de Renan, quien señaló que en la historia de la humanidad los pequeños grupos sociales de los inicios de nuestra historia, que por lo general iniciaron con clanes familiares, se fueron integrando hasta conformar las grandes ciudades de la antigüedad de miles de personas y de allí se pasó a constituir las naciones de hoy que cuentan con millones de seres humanos.

El proceso de concentración urbana ha sido uno de los principales factores históricos al momento de considerar las características culturales e identitarias, ya que al vivir juntos compartían lengua, religión, oficios, leyes o códigos morales y sobre todo las fronteras geográficas y, en opinión de Renan la concepción de raza ${ }^{5}$; principios, todos ellos, insuficientes para explicar la conformación de una nación.

Antes de continuar con Renan, debo señalar que en América Latina y el Caribe, ya no se habla de raza, sino que se retoma la noción de etnias, sin embargo, para no romper con el discurso del pensador francés, sólo apunto esta referencia. En opinión de Renan, las actuales naciones obedecen más su establecimiento a los esfuerzos de personajes específicos, en el caso de Francia, fueron los Capeto quienes contribuyeron a forjar dicha nación; sin embargo, en otros casos fue por la voluntad directa de los pobladores de las provincias, como en Holanda y Bélgica o por un espíritu general tardíamente vencedor de los caprichos del feudalismo como en Italia y Alemania. Sin embargo, para Renan, el rasgo principal consiste, como ya se había señalado, en una dinastía que representa una antigua conquista, la cual fue aceptada y posteriormente olvidada.

L. Zea, Elpensamiento latinoamericano, Barcelona 1976, p. 52 (Colección Demos).

5 Renan previamente señaló que las actuales naciones europeas iniciaron con una serie de invasiones violentas, por lo que es de suma importancia destacar que la identificación de raza con el de nación, como criterio más directo, es falso, debido a que las invasiones y la mezcla de razas fue una práctica tan profunda que es casi imposible mantener esa idea. En este sentido, apuntó que Pese a la extrema violencia de costumbres de los invasores germánicos, el molde que impusieron llegase a ser, con el paso de los siglos, el molde mismo de la nación. "Francia" se convirtió con toda legitimidad en el nombre de un pais donde no habia entrado más que una imperceptible minoría de francos - E. Renan, ¿Qué es una nación?..., p. 64. 
En este sentido, es por la voluntad específica de unos seres humanos que se han conformado naciones, en etapas o momentos históricos que han unido en una población a amplios sectores sociales.

Antes de avanzar, considero oportuno detenerme para señalar que, hoy día, existen otras concepciones de la manera cómo en la modernidad se caracterizó a la nación, sobre todo vinculándola al Estado, entendido éste como un ordenamiento jurídico, cuya finalidad es la construcción, ejercicio y mantenimiento del poder soberano en un territorio delimitado, al que están subordinados de manera necesaria los individuos que le pertenecen. De tal modo, lo importante del trabajo de Renan es que permitió introducir el estudio de la nación y la concepción del olvido de lo traumático para lograr su consolidación.

Con esta base, es posible señalar que en opinión de Renan, la nación moderna se constituye por un principio espiritual, que se conforma de dos partes; una está en el pasado y la otra en el presente. La primera es el rico legado de recuerdos en común. La segunda, es el consentimiento de vivir en conjunto. Así, el culto a los antepasados es la forma más legítima de honrar la historia y fortalecer el actual sentido de vida en sociedad. Así, en el pasado heroico se asienta una idea nacional. Tener glorias comunes en el pasado, una voluntad común en el presente; haber hecho grandes cosas juntos, querer hacerlas todavia, he aqui las condiciones esenciales para ser un pueblo. Se ama en proporción a los sacrificios soportados, a los males sufridos ${ }^{6}$.

De tal modo que, los miembros integrantes de una nación hoy día deben de compartir tres aspectos: a) del pasado una gloria común; b) en el presente retos y fracasos; c) en el porvenir un mismo programa a realizar. Precisamente en este último aspecto deben de dirigirse nuestras reflexiones, ya que en los programas de gobierno de los distintos países de América Latina se han olvidado de construir proyectos de integración de la diversidad.

Por la falta de un programa a realizar en conjunto que beneficie a los diversos grupos humanos, plantear el olvido de los males padecidos por la población, desde la conquista hasta la actualidad, resulta impensable en América Latina; precisamente por ello, es que los diversos grupos étnicos han buscado fortalecerse a través de establecer alianzas entre ellos y, por lo tanto, distanciándose de los gobiernos nacionales, por lo que el debate sobre las características de las relaciones interculturales, es muy importante.

\section{QUÉ ES UNA NACIÓN}

Ahora bien, aunque el trabajo de Ernest Renan es interesante, es necesario señalar que con el concepto de nación, en realidad se está haciendo referencia a diversas formaciones sociopolíticas.

En este orden de ideas, el concepto aportado por Renan alude a un sentido moderno del concepto nación; sin embargo, existen otras acepciones que guardan relación

$6 \quad$ Ibid., p. 83. 
con formas sociales de identificación colectiva. Como lo señala Héctor Díaz Polanco Un grupo humano se constituye como nación cuando sus miembros se reconocen mutua $y$ firmemente ciertos deberes y derechos en virtud de su común calidad de miembros. Es ese reconocimiento del prójimo como individuo de su clase lo que los convierte en nación, no los demás atributos cualesquiera que puedan ser ${ }^{7}$. Por lo que en su opinión no sólo son factores étnico-culturales, sino también las luchas internas de clases.

Considero oportuno recordar que el concepto de etnia está relacionado con el de nación. Sin embargo, la acepción de nación en su sentido étnico, es diferente al concepto de nación en su acepción política. Debido a que esta última se comprende dentro de un marco de instituciones, así como de códigos legales surgidos bajo las ideas rectoras de las tradiciones liberales, federales y republicanas de diversos países de Europa y de los Estados Unidos. Por lo que no se ajustan y menos aceptan a las instituciones y leyes (llamados en México, usos y costumbres) de los grupos originarios. Con lo que se está marcando una diferencia entre los ciudadanos que heredaron los sistemas políticos de organización social prehispánicos, de aquellos que viven en la tradición occidental.

En todo caso, es necesario hacer notar que el sistema político de bases liberales, republicanas y federales que rige en la mayoría de los países latinoamericanos, no acepta otros diferentes, debido a que así se debilitaría su sistema de legitimación. Sólo como un ejemplo, podemos mencionar el caso de las votaciones, debido a que si un gobierno no alcanza un porcentaje razonado de votos, entonces no puede ostentarse como un representante válido de la población.

Así, con base en la necesidad de legitimación del sistema político de corte liberal, es que no es posible aceptar otros sistemas políticos que puedan conducir a transformaciones que beneficien a la población. Sobre todo si consideramos que no estamos hablando de uno o dos grupos humanos, sino que en realidad se está abordando una situación compleja, por ejemplo en México es posible hablar de más de cuatrocientos pueblos originarios, pero no sólo ello, sino que además es necesario reconocer la existencia de agrupaciones o asociaciones diversas, que también están luchando por reconocimiento y establecimiento de diversas leyes, entre ellos los grupos feministas, los lésbico-gay, sin olvidar a las organizaciones en defensa de la ecología, de los animales, en contra del maltrato a las mujeres, entre otras. Sin olvidar a las comunidades de migrantes, así como a las organizaciones religiosas.

De tal modo, que si se consideran la diversidad de intereses que se pueden gestar en una nación, entonces es obvia la necesidad, de cualquier grupo que esté en el gobierno, de mantener todo bajo control, pues de no ser así, sería imposible gobernar y cumplir con los acuerdos establecidos antes de llegar al poder, lo cual es contrario a la libertad de la población.

En este punto me considero en la posibilidad de señalar que el problema de la diversidad cultural, no se puede resolver si no se entiende la manera como en las relaciones interculturales se busca el ejercicio de postura ética, en el que prive el respeto a la dig-

H. Díaz Polanco, 'Las minorías étnicas como categoría política en la cuestión regional' en idem, La cuestión étnico-nacional, México 1988, p. 7 (Fontamara, 53). 
nidad y el bienestar de las personas, ello posibilitará una convivencia entre los diversos grupos humanos que habitan en América Latina y el Caribe.

\section{EL RETO IDENTITARIO}

Es el momento de abordar el reto identitario, que desde nuestro punto de vista exige una breve recuperación de las ideas expuestas. Por lo que en primer lugar es necesario señalar que la búsqueda identitaria es una constante humana, a través de la cual encontramos arraigo, tanto en lo individual como en lo comunitario. Sin embargo, esa adscripción grupal, construye un nosotros y un ellos, es decir, estableciéndose una diferencia.

En el caso de América Latina, que desde la época independiente ha pretendido eliminar las diferencias con la intención "buena o mala", "verdadera o falsa" de crear un grupo humano unificado resultó un fracaso, debido a que en los proyectos de construcción nacional, no se los consideró como grupos que también tenían derecho a gozar de la riqueza nacional.

Ahora, se debe aceptar que las identidades nacionales nacidas de las invenciones de los Estados del siglo XIX, no han conseguido unificar la diversidad cultural y no hay indicios de que ello pueda ocurrir. No por el hecho de que los grupos originarios no se sientan pertenecientes a una nación, sino porque los Estados los han marginado. De allí la importancia que hoy día han adquirido las experiencias de integración supranacional. Cuyo ejemplo más reciente son la Comunidad Andina, la Comunidad Centroamericana e incluso, por qué no señalarlo la experiencia del EZLN en México al integrar a diversas etnias.

\section{LAS INTEGRACIONES SUPRANACIONALES}

En primer lugar es necesario destacar lo que vamos a entender por supranacionalidad. Para ello es importante citar las ideas expresadas por Jaime Delgado, quien señala que la supranacionalidad se constituye por Estados cuya vecindad regional les ha aportado algún proyecto político más o menos compartido y cierto grado de identidad'.

Desde esta perspectiva consiste en una integración resultado de la expresión política de los Estados de fortalecer sus vínculos. Para este trabajo, es importante destacar dos de las propuestas más perfeccionadas: 1) La Alternativa Bolivariana para los pueblos de Nuestra América (ALBA), en la que interesa destacar los acuerdos comerciales, llevados a cabo con el pueblo de Cuba y, 2) La Comunidad Andina de Naciones (CAN, previamente Pacto Andino), que inició un proyecto de integración regional basada en la planificación industrial.

8 J.G. Delgado Rojas, 'Integración y supranacionalidad en América Latina' en R. Páez Montalbán, M. Vázquez Olivera (coords.), Integración latinoamericana. Raices y perspectivas, México 2008, p. 184 (Colección Miradas del Centauro). 
Otra forma de organización supranacional, la han llevado a cabo las naciones originarias. En este sentido, un dato importante es que hasta el presente los acuerdos de integración han sido dirigidos por los Estados nacionales que se estimule el trabajo independiente de los pueblos originarios y que si bien es cierto se han logrado algunos avances importantes. Como un ejemplo, es posible citar el acta de instalación de la mesa de los pueblos andinos de la comunidad andina, que se llevó a cabo el 11 de mayo de 2002 en Urubamba, Cuzco - Perú, en donde los representantes de las organizaciones indígenas de Bolivia, Colombia, Ecuador, Perú y Venezuela, se reunieron para fortalecer sus lazos, por lo que recordaron que habían obtenido significativos acuerdos en cuanto al reconocimiento político y jurídico, así como las iniciativas económicas destinadas a impulsar el crecimiento de las poblaciones andinas.

Ahora bien, es de suma importancia considerar los avances en cuanto al reconocimiento, sin embargo, todavía hoy las comunidades andinas siguen siendo las más golpeadas. Por lo que es importante que continúen trabajando para concretar el respeto a sus pobladores, para ello es necesario que su experiencia los conduzca hacia el trabajo independiente, esto es a no atenerse a pautas políticas establecidas por las instituciones mundiales y menos de las establecidas por sus respectivos países, a menos de que efectivamente acepten sus propuestas de construcción de gobierno. Por lo que es preciso profundizar en los acuerdos, a partir de sus necesidades, exigencias y proyectos, con ello podrán cumplir una parte muy importante de los Acuerdos Supranacionales, la creación de un nuevo orden jurídico, en donde hay una primacía del Derecho Comunitario ${ }^{9}$.

\section{CONCLUSIONES}

Así como en otras regiones de América Latina y el Caribe, en México los grupos originarios se están organizando para concretar un reconocimiento así como trato justo y diferenciado. Así, también se están llevando a cabo acciones similares, de ahí que el ejemplo más destacado continúe siendo el del EZLN.

Sin embargo, coincido con las opiniones las cuales señalan que para concretar sus objetivos, es necesario recuperar la tradición republicana legada por Roma y traída a la Nueva España por los hispanos, debido a que en dicho sistema de organización se ponía énfasis en la virtud de los ciudadanos y la convicción de que hay un bien público más allá de los intereses de los particulares ${ }^{10}$. En dicha propuesta, lo público adquiere mayor importancia que lo privado.

En este orden de ideas, para atender los actos de consecuencias amplias, lo público necesita de formar medidas especiales, así la idea del espacio público es la de un conjunto de mecanismos para tratar con los problemas colectivos, por lo cual lo público es, por asi de-

J.G. Delgado Rojas, 'Integración y supranacionalidad...', p. 185.

10 F. Escalante Gonzalbo, Ciudadanos imaginarios. Memorial de los afanes y desventuras de la virtudy apología del vicio triunfante en la República Mexicana. Tratado de moral pública, México 1998, p. 35. 
cirlo, una solución inevitable, casi espontánea, de los problemas que supone la coexistencia pacifica ${ }^{11}$.

Para concluir quiero exponer la situación en México, en donde el EZLN, exigió una representación más equitativa y una nueva reorganización federal que refleje el pluralismo cultural y promueva una descentralización política en beneficio de los poderes locales, principalmente municipales.

Desdichadamente, en México a pesar de que en el artículo $2^{\circ}$ de la Constitución se lee: La nación tiene una composición pluricultural sustentada originalmente en sus pueblos indigenas que son aquellos que descienden de poblaciones que habitan en el territorio actual del pais al iniciarse la colonización y que conservan sus propias instituciones sociales, económicas, culturales y politicas, o parte de ellas.

Inicio de artículo bastante benéfico. Infortunadamente en otro párrafo se lee: La federación, los estados y municipios, para promover la igualdad de oportunidades de los indigenas y eliminar cualquier práctica discriminatoria, establecerán las instituciones y determinarán las politicas necesarias para garantizar la vigencia de los derechos de los in dígenas y el desarrollo integral de sus pueblos y comunidades, las cuales deberán ser diseñadas y operadas conjuntamente con ellos ${ }^{12}$.

De tal modo, como lo señaló Ambrosio Velasco en lugar de reconocer a los pueblos indígenas como sujetos de derecho público se los reconoce como entidades de "interés público" para la política de asistencia social.

Por lo que constitucionalmente en este artículo se debería leer: La federación, los estados y municipios, para promover la igualdad de oportunidades de los indigenas y eliminar cualquier práctica discriminatoria, por lo que reconocen las normas propias de cada pueblo para la elección de autoridades y creación de instituciones, como sistemas politicos de gobierno. Por lo que serán capaces de decidir e interactuar con los gobiernos nacionales y establecer los Acuerdos de Integración Supranacionales pertinentes, para desarrollo cultural, político y económico.

Ahora, no es ingenuidad pensar que con el simple hecho de que en la Constitución mexicana se les reconozca a las naciones originarias el derecho a erigir sus propias instituciones, bastará para solucionar sus problemas, ya que seguramente será necesario reelaborar otros artículos para que efectivamente puedan llevar a cabo sus planes. Claro además que aparecerán los intereses particulares que tratarán de impedir que se lleve a cabo.

Sin embargo, sólo a través de reconocer el derecho de los pobladores de las naciones originarias a su derecho a la autodeterminación, podrán concretar sus proyectos de bienestar comunitario. Sobre todo, porque en México ya hay ejemplos de ello, ya que no se debe olvidar la legislación de Oaxaca que ya permite las autonomías. Claro que debido al control político que el Estado ha ejercido sobre dichas poblaciones, ese sistema político no ha florecido. Pero lo que quiero enfatizar que no es imposible que las naciones originarias puedan avanzar en la conquista de sus derechos.

11 Ibid.

12 Constitución politica de los Estados Unidos Mexicanos, México 2005, p. 6. 


\section{BIBLIOGRAFÍA}

Constitución politica de los Estados Unidos Mexicanos, México 2005.

Escalante Gonzalbo F., Ciudadanos imaginarios. Memorial de los afanes y desventuras de la virtud y apología del vicio triunfante en la República Mexicana. Tratado de moral pública, México 1998.

Delgado Rojas J.G., 'Integración y supranacionalidad en América Latina' en R. Páez Montalbán, M. Vázquez Olivera (coords.), Integración latinoamericana. Raíces y perspectivas, México 2008 (Colección Miradas del Centauro).

Díaz Polanco H., 'Las minorías étnicas como categoría política en la cuestión regional' en idem, La cuestión étnico-nacional, México 1988 (Fontamara, 53).

Mora Martínez R., 'Los tres pilares de la filosofía latinoamericana', Archipiélago, Año 20, Núm. 80 (2013).

Renan E., ¿Qué es una nación? Cartas a Strauss, Madrid 1987 (Libro de Bolsillo, 1294. Humanidades).

Zea L., Elpensamiento latinoamericano, Barcelona 1976 (Colección Demos).

Dr Roberto MORA MARTÍNEZ - Doctor en Estudios Latinoamericanos por la UNAM. Investigador del Centro de Investigaciones Sobre América Latina y el Caribe (CIALC-UNAM). Profesor de en la Licenciatura de Estudios Latinoamericanos de la FFyL-UNAM. Ha sido Secretario académico del Programa de Posgrado en Estudios Latinoamericanos UNAM. Autor de: Temas y problemas de filosofía latinoamericana, México 2012; Consideraciones sobre el hombre y la intencionalidad espiritual. Estudio basado en la propuesta de Francisco Romero, México 2012; La fuerza del mito de lo gaucho. Fundamento del nacionalismo argentino desde la visión del filósofo Carlos Astrada, México 2010; Actualmente es responsable de los proyectos de investigación: Afluencias, confluencias y divergencias de los estudios latinoamericanos y los estudios culturales y subalternos, Clave IB400113. DGAPA-PAPIIT. 